\title{
The association of Boeremia lilacis with necrotic lesions on shoots and leaf petioles and its pathogenicity towards Fraxinus excelsior
}

\author{
T. Kowalski • W. Kraj • B. Bednarz • R. Rossa
}

Accepted: 7 March 2019 / Published online: 23 April 2019

(C) The Author(s) 2019

\begin{abstract}
This paper reports the results of the study on the new type of necrotic lesion observed on epicormic shoots and leaf petioles of Fraxinus excelsior showing ash decline symptoms in stands of the Miechów Forest District, southern Poland. The performed symptom analysis included: shape and size of necroses, discoloration of necrotic tissue and the occurrence of fungal fructification. The same species of fungus, which was initially identified as Boeremia exigua, was isolated from $97 \%$ of epicormic shoots and from $82 \%$ of leaf petioles. However, detailed morphological and physiological ( $\mathrm{NaOH}$ test) analyses and combined ITS, ACT, TUB and EF1- $\alpha$ phylogeny proved these isolates to belong to Boeremia lilacis, the species known so far as Syringa vulgaris pathogen occurring occasionally also on Forsythia hybrids or Philadelphus. Fraxinus excelsior is reported for the first time as a host for this fungus. To clarify the possible role of B. lilacis in development of necrotic lesions on ash, 10 randomly selected isolates were tested for their pathogenicity toward young $F$. excelsior plants using the method of artificial wound inoculation under field conditions. The isolates used in the test caused tissue necroses on all 60 inoculated shoots and all 60 inoculated
\end{abstract}

T. Kowalski $(\bowtie) \cdot$ W. Kraj

Department of Forest Pathology, Mycology and Tree Physiology, University of Agriculture in Krakow, Kraków, Poland e-mail: rltkowal@cyf-kr.edu.pl

B. Bednarz $\cdot$ R. Rossa

Department of Forest Protection, Entomology and Forest Climatology, University of Agriculture in Krakow, Kraków, Poland leaf petioles. Necrotic lesions developed as a result of artificial inoculation corresponded largely to the symptoms following natural infections.

Keywords Boeremia lilacis $\cdot$ Pathogenicity assay Necrotic lesion

\section{Introduction}

Common ash (Fraxinus excelsior L.) for over two decades has been threatened in Europe by ash dieback caused by the ascomycete Hymenoscyphus fraxineus (Kowalski 2006; Bakys et al. 2009; Queloz et al. 2011; Husson et al. 2012; Baral et al. 2014; Gross et al. 2014; McKinney et al. 2014). According to the current knowledge, $H$. fraxineus originates from Asia, where it is associated with Fraxinus mandshurica and $F$. chinensis subsp. rhynchophylla (Baral et al. 2014; Gross et al. 2014; Gross and Han 2015; Drenkhan et al. 2017).

Hymenoscyphus fraxineus produces its apothecia mainly on leaf debris of the previous year lying in the litter (Gross et al. 2014), where ascospores mature during summer and spread the infection on living trees (Timmermann et al. 2011; Cleary et al. 2013; Baral and Bemmann 2014; Gross et al. 2014). Disease symptoms include necrotic lesions on leaves or other infected parts of trees, dieback of shoots, twigs and branches in the crown. Severely affected trees respond to branch dieback by formation of epicormic shoots (Skovsgaard et al. 2010; McKinney et al. 2014). Such shoots developed at the base of the stem are suitable entry points for 
new infections, what may result in rapid death of the tree (Husson et al. 2012; Gross et al. 2014).

On such epicormic shoots of symptomatic F. excelsior trees a new type of necrotic lesions has been frequently observed in southern Poland since 2010. Since 2013 ash leaf petioles also started to show necrotic lesions that differed from these caused by $H$. fraxineus (Kowalski and Holdenrieder 2009; Cleary et al. 2013; Kowalski and Kehr 2016; Drenkhan et al. 2017).

For most analysed shoots and leaf petioles fungal isolations proved that necroses harboured a species of fungus that, based on morphology, could be initially identified as Boeremia exigua (Desm.) Aveskamp, Gruyter \&Verkley (basionym: Phoma exigua Desm.) (Aveskamp et al. 2010).

Boeremia exigua has a worldwide distribution in agriculture, horticulture and forestry (Farr et al. 1989; Brebaum and Boland 1999; Boerema et al. 2004), found also on various ash species (Ibrahim et al. 2017; Kosawang et al. 2017; Power et al. 2017). It occurs on F. excelsior as both: an endophyte in tissues of asymptomatic trees (Chen 2012; Schlegel et al. 2016; Power et al. 2017) and leaves or shoots of ash decline symptomatic trees (Kowalski et al. 2016; Bakys et al. 2009; Trapiello et al. 2017). The B. exigua associated symptoms, however, are described in detail only for young seedlings in nurseries (Boudier 1994; Schmitz et al. 2006).

Taxonomically $B$. exigua is considered to be an assemblage of over ten varieties (Boerema and Höweler 1967; Aa et al. 2000; Aveskamp et al. 2010; Berner et al. 2015). Thus, morphological identification is often supported by molecular methods (Abeln et al. 2002; Aveskamp et al. 2009, 2010; Berner et al. 2015). Among several identification methods of Boeremia/Phoma species and varieties, based on gene or sets of gene sequencing such as combined cox 1 and ITS, calmodulin, $\beta$-tubulin and translation elongation factor 1- $\alpha$ or fragment of actin gene (Aveskamp et al. 2009, 2010; Berner et al. 2015), the best method to identify our isolates was the four gene based (ITS, ACT, TUB and EF1- $\alpha$ ) phylogenetic analysis as described in Berner et al. (2015).

Usually the variety level identification of Boeremia exigua isolates originating from both, diseased and asymptomatic $F$. excelsior trees, was not carried out (Chen 2012; Bakys et al. 2009; Kowalski et al. 2016; Schlegel et al. 2016; Ibrahim et al. 2017; Power et al. 2017). Occasionally, when the variety was reported, it was var. exigua (Schmitz et al. 2006).
Due to high variation within Boeremia exigua and bearing in mind the fact that the cause for observed necroses may be other Boeremia species, previously unknown from $F$. excelsior, we decided to conduct a detailed morphological and molecular analysis of isolates originating from necrotic lesions on ash epicormic shoots and ash leaf petioles collected in southern Poland. Another aim of this study was to test these isolates for their pathogenicity toward living tissues of $F$. excelsior using the local wound inoculation method. This method proved to be effective in testing other species of fungi allowing to assess the level of their pathogenicity (Kowalski et al. 2017; Gross and Sieber 2016).

\section{Materials and methods}

Sampling, isolation of pure cultures and identification of fungi in necrotic lesions

A total of 100 epicormic shoots (2-5 shoots from a single tree, a total of 30 trees) with visible necrotic lesions were collected at random in the spring and autumn seasons of 2010-2013 in various stands of Miechów Forest District, southern Poland (Table 1). All shoots developed on stems of 25-40 years old F. excelsior trees showing symptoms of ash dieback. All samples were stored in a fridge $\left(5^{\circ} \mathrm{C}\right)$ until the symptom analysis. The analysis included assessment of size, shape and colour of necrotic tissue of the lesions and the occurrence of bark cracks. Any occurring fungal fruiting bodies were identified following the procedure by Kowalski et al. (2016). When Boeremia exigua - like pycnidia were noticed they were used at random to obtain cultures from spores for comparative purposes.

A single necrotic lesion was used for each shoot to isolate fungi, all isolations were carried out within $24 \mathrm{~h}$ after collection, according to the method described by Kowalski et al. (2016). In total, isolations were made from 516 pieces from 100 necrotic lesions. The incubation took place at $20{ }^{\circ} \mathrm{C}$ in darkness. All Petri dishes were examined every 3-7 days for at least 6 weeks. Different fungal taxa detected on different tissue pieces on the same agar plate were sub-cultured and re-grown on new agar plates. All isolated fungi were grouped into morphotypes. Their identification was based on the colony appearance and fructification as well as on the size and shape of conidia. 
Table 1 Isolates of Boeremia lilacis from necrotic lesion on epicormic shoots (ES) or petioles (P) of F. excelsior in Miechów Forest District used in the present study and GenBank accession numbers for actin (ACT), $\beta$-tubulin (TUB) and translation elongation factor- $1 \alpha(\mathrm{EF}-1 \alpha)$ and $\mathrm{rDNA}$ (ITS) sequences

\begin{tabular}{|c|c|c|c|c|c|}
\hline \multirow[t]{2}{*}{ Isolate no. } & \multirow[t]{2}{*}{ Plant organ } & \multicolumn{4}{|c|}{ GenBank accession number } \\
\hline & & $\mathrm{ACT}$ & TUB & $\mathrm{EF}-1 \alpha$ & ITS \\
\hline Js 4353 & $\mathrm{P}$ & MG967688 & MG967698 & MG967678 & MG852163 \\
\hline Js 6730 & $\mathrm{ES}$ & MG967689 & MG967699 & MG967679 & MG852164 \\
\hline Js 6731 & ES & MG967690 & MG967700 & MG967680 & MG852165 \\
\hline Js 6738 & $\mathrm{ES}$ & MG967691 & MG967701 & MG967681 & MG852166 \\
\hline Js 6742 & ES & MG967692 & MG967702 & MG967682 & MG852167 \\
\hline Js 6764 & ES & MG967693 & MG967703 & MG967683 & MG852168 \\
\hline Js 6866 & ES & MG967694 & MG967704 & MG967684 & MG852169 \\
\hline Js 6874 & $\mathrm{P}$ & MG967695 & MG967705 & MG967685 & MG852170 \\
\hline Js 6915 & ES & MG967696 & MG967706 & MG967686 & MG852171 \\
\hline Js 9032 & ES & MG967697 & MG967707 & MG967687 & MG852172 \\
\hline
\end{tabular}

In 2013 and 2014, necrotic lesions on ash leaf rachises and petioles (collectively treated here as petioles), different from these caused by $H$. fraxineus, were observed in the same tree stands. A total of 50 ash leaves (2-3 leaves from 20 trees) with such lesions were collected at random from lower parts of crowns. The extension of necrotic lesions and discoloration of the tissue were assessed in laboratory observations. Fungal isolations were carried out from 50 necrotic lesions (300 fragments), following the same procedure as for epicormic shoots.

Since the most frequent fungus isolated from necrotic lesions was a species similar to $B$. exigua, only the isolates of this morphotype were used in downstream in vitro and pathogenicity tests. Ten randomly selected isolates were used for these analyses: eight originating from necrotic lesions on epicormic shoots and two from necrotic lesions on ash leaf petioles (Table 1).

Morphological and molecular characteristics

The colony characteristics were determined in two week old cultures on the basis of colour of the mycelium, structure, outline of the colony, growth rate, colour of the conidial matrix upon sporulation (Boerema et al. 2004). Production of crystal-like structures was also observed in two week old cultures. Micromorphological features were studied after maturation of the pycnidia. The fungal structures were mounted in tap water using a scalpel blade. The size ranges of conidiomatal pycnidia and conidia were determined based on five or 30 samples of each culture, respectively. The $\mathrm{NaOH}$ spot test was carried out by application of a droplet of $1 \mathrm{~N} \mathrm{NaOH}$ to determine the secretion of metabolite $\mathrm{E}$ on MEA cultures (Boerema et al. 2004).

Total genomic DNA was extracted following the modified procedure of Khanuja et al. (1999). Molecular identification was conducted based on four barcode sequences: ITS region of ribosomal DNA (including ITS1, 5.8S and ITS2) and the fragments of actin (ACT), $\beta$-tubulin (TUB) and translation elongation factor- 1 alpha (EF-1 $\alpha$ ) genes, using the following PCR primers: ITS: ITS1 (5'-TCCGTAGGTGAACCTTGCGG-3') and ITS4 (5'-TCCTCCGCTTATTGATATGC-3') (White et al. 1990), ACT: ACT-512F (5'-ATGTGCAAGGCCGG TTTCGC-3') and ACT-783R (5'-TACGAGTC CTTCTGGCCCAT-3') (Carbone and Kohn 1999), TUB: BT2A (5'- GGTAACCAAATCGGTGCTGC TTTC-3') and BT2B (5'-AACCTCAGTGTAGT GACCCTTGGC-3') (Glass and Donaldson 1995) and EF-1 $\alpha$ : EF1-728F (5'-CATCGAGAA-GTTCGAGA AGG-3') and EF1-986R (5'-TACTTGAAGGAACC CTTACC-3') (Carbone and Kohn 1999).

PCR reactions were performed in $50 \mu$ of reaction mixture consisting of the following composition: PCR buffer $1 \times, \mathrm{MgCl}_{2} 2 \mathrm{mM}$, dNTP $0.2 \mathrm{mM}$ each (Thermo Fisher Scientific, Waltham, MA, USA), primers $0.5 \mu \mathrm{M}$ each, DNA Dream Taq Green polymerase $1 \mathrm{U}$ (Thermo Fisher Scientific, Waltham, MA, USA) and $50 \mathrm{ng}$ of template DNA. DNA amplification was run in an 
Eppendorf Mastercycler EP Gradient S thermocycler (Eppendorf AG, Hamburg, Germany) using the following programme: initial denaturation at $95{ }^{\circ} \mathrm{C}$ for $5 \mathrm{~min}$, followed by 36 cycles composed of denaturation at $95{ }^{\circ} \mathrm{C}$ for $1 \mathrm{~min}$, annealing at: $54{ }^{\circ} \mathrm{C}$ (ITS), $56{ }^{\circ} \mathrm{C}$ (ACT), $57{ }^{\circ} \mathrm{C}$ (TUB) or $55{ }^{\circ} \mathrm{C}(\mathrm{EF}-1 \alpha)$ for $2 \mathrm{~min}$, elongation at $72{ }^{\circ} \mathrm{C}$ for $2.5 \mathrm{~min}$. The elongation of the last cycle was increased to $8 \mathrm{~min}$. The effectiveness of PCR and the length of the amplified DNA fragments was verified by $1.5 \%$ agarose gel electrophoresis.

The purification and sequencing of PCR products using ITS1, ACT-512F, BT2A and EF1-728F primers was carried out by Macrogen Europe (Amsterdam, The Netherlands). Sequences were edited and identified by searching the most similar sequences in NCBI GenBank using Geneious Pro R11 (Biomatters, Auckland, New Zeland) (Kearse et al. 2012) and BLAST+ algorithm (Basic Local Alignment Search Tool). Sequences of Boeremia isolates were deposited in GenBank (Table 1).

Sequences for all four target regions, ITS, ACT, TUB and EF1- $\alpha$, were combined and aligned jointly with MAFFT v. 7.388 module implemented in Geneious Pro R11 (Katoh and Standley 2013). The aligned lengths for particular fragments were as follows: $475 \mathrm{bp}$ for ITS, $230 \mathrm{bp}$ for ACT, $215 \mathrm{bp}$ for TUB and $276 \mathrm{bp}$ for EF1- $\alpha$, in total $1196 \mathrm{bp}$. The number of base substitutions per site was calculated using Maximum Composite Likelihood model (Tamura et al. 2004) with MEGA 7.0 software (Kumar et al. 2016) to demonstrate the mean pairwise distance between pairs of combined sequences. The analysis included sequences of Polish $B$. lilacis isolates, the most similar sequences of B. lilacis (CBS 569.79, CBS 489.94 and CBS 101206) and sequences of other Boeremia species/ varieties. Numbers of parsimony informative and singleton variable sites were counted in each gene using DnaSP 6.0 software (Rozas et al. 2017). This data-set was used in phylogenetic analysis whose purpose was to determine the species / variety of Boeremia isolates used in the pathogenicity test. The analysis included sequences for all isolates acquired in this study and three B. lilacis isolates currently available in GenBank database (Aveskamp et al. 2009; Berner et al. 2015). We also used sequences for 33 isolates of different varieties of B. exigua and 17 isolates of other Boeremia species (Berner et al. 2015). The analysis itself was carried out in MEGA 7.0 software (Kumar et al. 2016) using maximum likelihood (ML) method. The same programme was used to determine the best-fitted DNA substitution model, according to both: Akaike Information Criterion (AIC) and Bayesian Information Criterion (BIC) the best substitution model was $\mathrm{HKY}+\mathrm{G}$ (Hasegawa et al. 1985). Node support valuses in the phylogenetic tree was evaluated in 1000 bootstrap replications.

\section{Pathogenicity tests}

All pathogenicity tests were conducted on an experimental plot located in the Stary Sacz Forest District, southern Poland (49 33' 83" N, $20^{\circ} 39^{\prime} 35^{\prime \prime}$ E), using eight -year-old Fraxinus excelsior seedlings. The trees, grown from seeds collected from ash trees in compartments 38f and 71d of Stary Sącz Forest District, grew in an open field (approximate spacing $1.0 \times 0.3 \mathrm{~m}$ ) and were not protected with fungicides. The inoculation method was similar to that used in earlier investigations (Kowalski et al. 2015). Ten isolates were used in inoculations, the characteristics of isolates are given in Table 1. They originated from necrotic lesions on F. excelsior epicormic shoots or leaf petioles collected in Miechów Forest District.

Inoculum production, inoculation and re-isolation were carried out according to the methods described by Kowalski et al. (2015). Shoots of the current season's growth $(0.5-0.7 \mathrm{~cm}$ thick) and leaf petioles were inoculated in the third decade of July 2015 (Table 2). The test was carried out in six replicates (six shoots and petioles inoculated on six plants) for each isolate. In total, 60 shoots and 60 petioles were inoculated with 10 fungal isolates. Control inoculations were performed for six shoots and six petioles.

The symptoms on shoots and petioles were assessed after 6 weeks. The lengths of superficially visible necrotic lesions were measured and the occurrence of fungal fructification was recorded. Re-isolations were attempted from all inoculated and control shoots and petioles within $24 \mathrm{~h}$ of harvesting. Three to six tissue pieces were taken from either inoculation wound, the advanced necrosis and from the lesion edge as described by Kowalski et al. (2015). The isolation from an organ was considered positive if the tested fungus grew from at least one tissue sample. In total, 270 samples from inoculated shoots, 270 samples from petioles and 36 samples from control plants were evaluated. 
Table 2 Occurrence of necroses on Fraxinus excelsior shoots and petioles six weeks post inoculation with Boeremia lilacis. Each isolate was used to inoculate six shoots and six petioles. All inoculated shoots $(n=60)$ and all inoculated petioles $(n=60)$ developed longitudinal necroses

\begin{tabular}{lll}
\hline Isolate no. & $\begin{array}{l}\text { Mean lenght of longitudinal necrosis } \\
\text { on inoculated shoots } \\
\pm \mathrm{SD}(\mathrm{mm})\end{array}$ & $\begin{array}{l}\text { Mean lenght of longitudinal } \\
\text { necrosis on petioles } \\
\pm \mathrm{SD}(\mathrm{mm})\end{array}$ \\
\hline Js 4353 & $16,50 \pm 1.87$ & $26,17 \pm 6.18$ \\
Js 6730 & $23,67 \pm 5.85$ & $32,83 \pm 8.18$ \\
Js 6731 & $15,50 \pm 1.52$ & $17,83 \pm 3.13$ \\
Js 6738 & $16,33 \pm 3.93$ & $17,50 \pm 5.01$ \\
Js 6742 & $21,00 \pm 4.82$ & $24,50 \pm 6.72$ \\
Js 6764 & $18,33 \pm 4.13$ & $24,50 \pm 8.96$ \\
Js 6866 & $19,83 \pm 5.60$ & $25,83 \pm 6.37$ \\
Js 6874 & $19,00 \pm 2.10$ & $27,33 \pm 13.05$ \\
Js 6915 & $24,17 \pm 5.00$ & $29,33 \pm 3.88$ \\
Js 9032 & $18,50 \pm 4.72$ & $33,00 \pm 3.22$ \\
\hline
\end{tabular}

Statistical analysis

The normality of data was verified using Shapiro-Wilk test. The statistical significance of differences in lesion length among two or more groups of variables was tested respectively by Mann-Whitney U test and a multiple comparisons post hoc test following KruskalWallis analysis of ranks. All statistical calculations were performed for significance level of $p=0.05$ using STATISTICA v. 12 (www.statsoft.com).

\section{Results}

Identification of Boeremia isolates

Five-day-old colonies growing from necrotic lesions were grey-beige with regular margin (Fig. 1a). After 14 days of cultivation in $20{ }^{\circ} \mathrm{C}$ on MEA they reached a diameter of $4.2-7.4 \mathrm{~cm}$ and turned olivegrey to olive-black, with floccose whitish-grey aerial mycelium, often with dark-grey patches, and with irregularly lobed margin (Fig. 1b). Chlamydospores were absent, but swollen, up to $8 \mu \mathrm{m}$ in diameter, olivaceous cells occurred, constricted at the septa. Pycnidia globose to subglobose partly submerged in the agar, $120-250 \mu \mathrm{m}$ in diameter, with ostiolum 25-50 $\mu \mathrm{m}$, conidial exudate salmon or peach coloured (Fig. 1c). Conidia aseptate 5.0-8.0 $\times 2.5-$ $3.5 \mu \mathrm{m}$, rarely 1 -septate $8.0-10.0 \times 3.0-4.0 \mu \mathrm{m}$, ellipsoidal, usually with small guttules (Fig. 1d). No antibiotic E production was observed, $\mathrm{NaOH}$ test was negative. However, white crystal-like structures occurred, most frequently produced during incubation at $25{ }^{\circ} \mathrm{C}$, whose clusters were most evident on the colony reverse.

Based on the morphological traits and sequences of ITS, ACT, TUB and EF1- $\alpha$, the presented here isolates used for pathogenicity tests were identified as Boeremia lilacis. The genetic relations among 10 isolates used in this experiment clearly showed that they are distinct from 11 varieties of Boeremia exigua and 8 other species of Boeremia (Aveskamp et al. 2009; Berner et al. 2015). All Polish isolates are genetically most similar to Boeremia lilacis strains (CBS 569.79, CBS 489.94 and CBS 101206) identified by Aveskamp et al. (2009) and create a unique and distinctive from other Boeremia species/varieties clade in Fig. 2. The mean $\%$ of identical sites for these two groups, i.e. Polish isolates and the only three available B. lilacis GenBank accessions, was 99.20, 98.76, 99.71 and 98.91 for ITS, ACT, TUB and EF1- $\alpha$ respectively. Particular sequences: ITS, ACT, TUB and EF1- $\alpha$, varied in number of parsimony informative sites $(7,25,22$ and 109 respectively), singleton variable sites $(55,40,20,25$ respectively) and mean \% of pairwise identity $(98.73,98.71,99.32$ and 97.12 respectively). They contained also fixed polymorphic sites allowing to distinguish $B$. lilacis from other Boeremia species / variables (one polymorphic site in both ACT and TUB genes and six polymorphic sites in EF1- $\alpha$ gene). The mean pairwise distance between Polish isolates of $B$. lilacis and other isolates of this species was 0.028 . This distance for other Boeremia species/varieties located in the second clade in Fig. 2 range from 0.051 to 0.078 . 
Fig. 1 Boeremia lilacis in vitro: a - cultures growing from necrotic lesions on ash epicormic shoots (after $5 \mathrm{~d}$ incubation), $\mathbf{b}$ - culture on MEA $\left(20^{\circ} \mathrm{C}, 2\right.$ weeks $), \mathbf{c}-$ colony fragment with pycnidia and salmon coloured conidial matrix, $\mathbf{d}$ - conidia $(\mathrm{bar}=10 \mu \mathrm{m})$
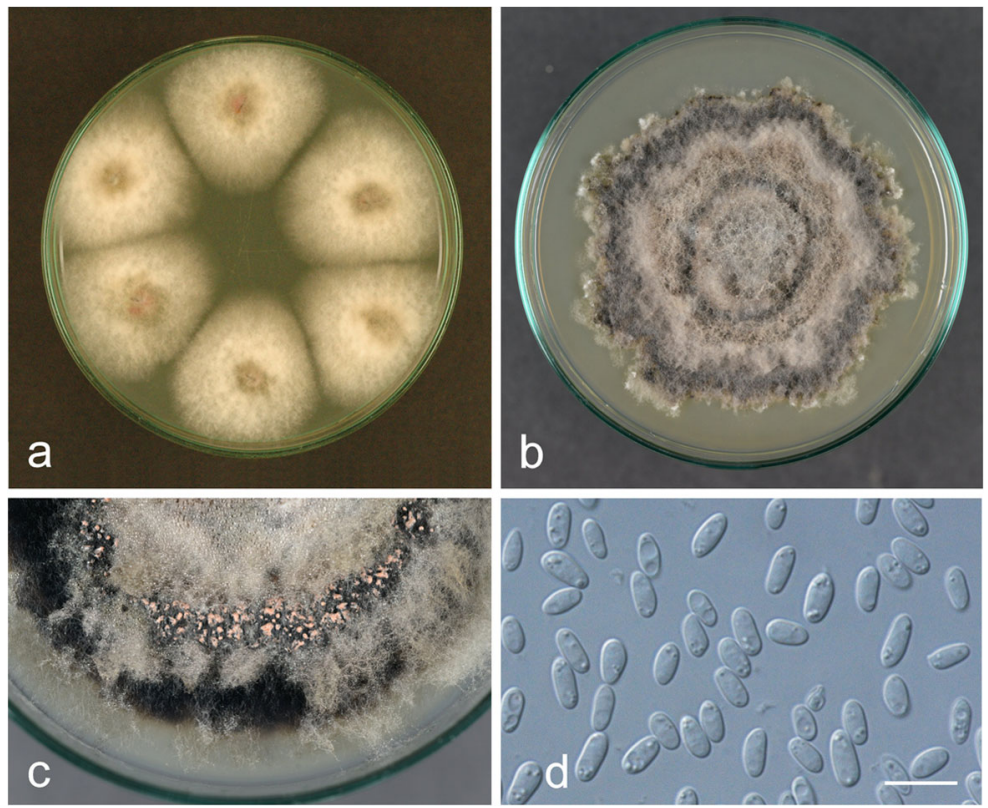

Natural necrotic lesions

For $53.0 \%$ of overall 100 natural necrotic lesions analysed on epicormic shoots, no distinct cracks were observed between necrotic tissue and surrounding inner tissues (Fig. 3a-c). At early development phase of lesions it could be observed that necrosis was formed initially around lenticels (Fig. 3a, b). For $3.0 \%$ of shoots necroses were located next to the bud. Necrotic lesions were round, oval, or shortly elliptical, sometimes slightly depressed (Fig. 3a-c), length mostly within $0.3-$ $2.3 \mathrm{~cm}$. For $41 \%$ of lesions a lengthwise rupture was observed what resulted sometimes in wood exposure and formation of callus (Fig. 3d, e). On some shoots local necroses coalesced forming large affected areas (Fig. 3e). For $6.0 \%$ of shoots dying top section was observed. Than a distinct narrowing formed at the base between dead and live sections of the shoot. Pycnidia of Boeremia lilacis (Fig. 3ce) developed on $27.0 \%$ of lesions. In addition, pycnidia of Phomopsis sp. were detected on one shoot and ascomata of Melanomma pulvis pyrius, once, directly on wood at the ruptured bark.

A total of 16 species of fungi were isolated from necrotic lesions. The most frequent was Boeremia lilacis that was detected in $97.0 \%$ of lesions. The known ash pathogen, Hymenoscyphus fraxineus was isolated from $3.0 \%$ of lesions. In addition species of genera: Fusarium, Hypoxylon, Lophiostoma, Melanomma, Paraconiothyrium, Phomopsis and Xylaria were isolated.

The length of the analysed necrotic lesions on ash leaf petioles ranged from 0.9 to $3.2 \mathrm{~cm}$ (Fig. 3f-j) mostly with uniformly dark-brown necrotic tissue (Fig. 3f). However, four petioles proved to have lighter, straw-coloured necrotic areas in the second half of growing season with multiple B. lilacis pycnidia (Fig. 3i, j). Then, small depressions of necrotic tissue could be observed (Fig. 3i, j). The transition from necrotic to living tissue was most often regular and sharply defined (Fig. 3f), less frequently necroses notched into living tissues (Fig. 3g). One to seven lenticels per necrotic area were observed. A total of 50 necrotic lesions on ash leaf petioles with characteristics described above were used in fungal isolations. In this experiment the presence of B. lilacis was confirmed in $41(82.0 \%)$ lesions and $H$. fraxineus in five $(10.0 \%)$ lesions, a single lesion harboured both species. In addition species of genera: Alternaria, Cladosporium, Colletotrichum, Epicoccum, Fusarium, Hypoxylon, Phomopsis and Paraconiothyrium were isolated.

Pathogenicity test

\section{Inoculated shoots}

All F. excelsior shoots inoculated with Boeremia lilacis developed necrotic lesions (Table 2, Fig. 4a- 


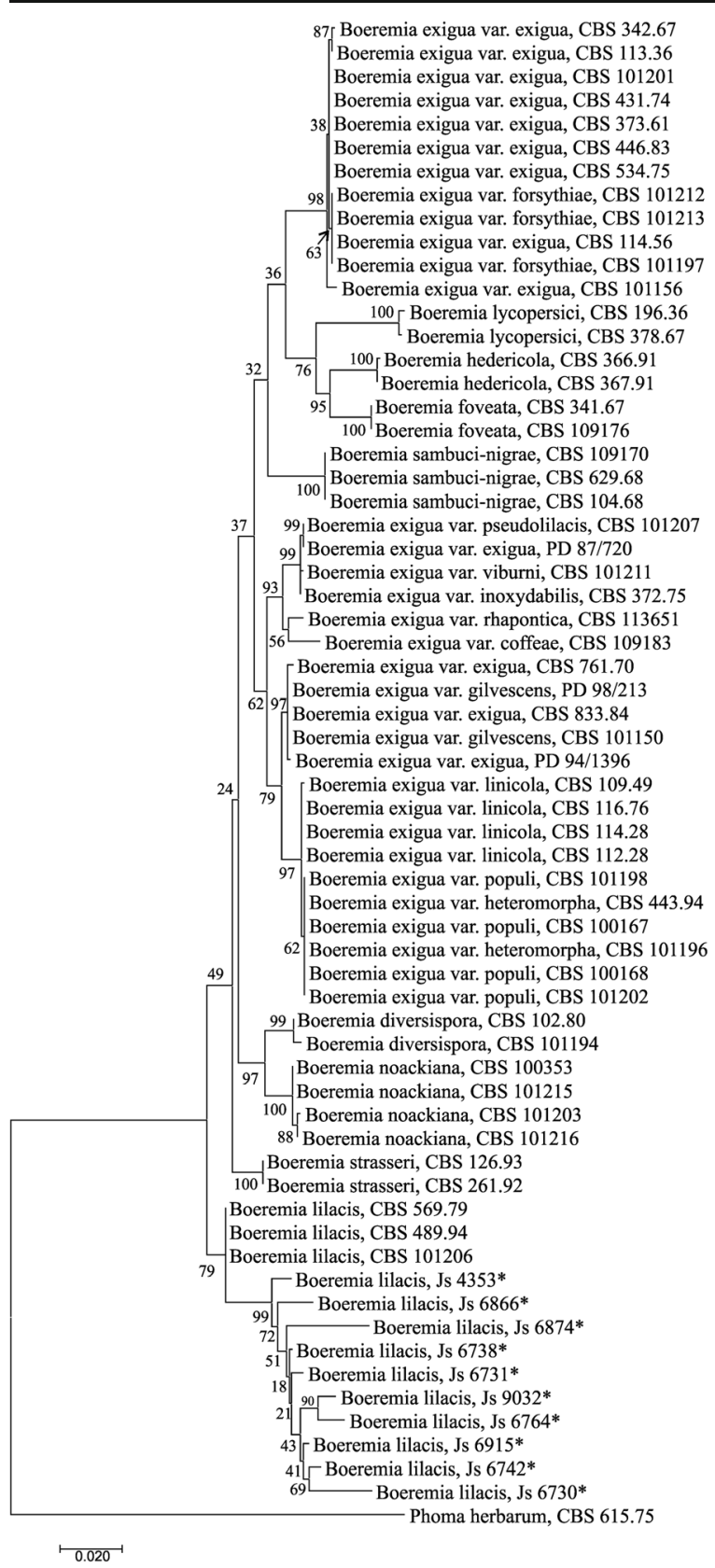

Fig. 2 Four-gene (ITS, ACT, TUB and EF1- $\alpha$ ) maximum likelihood phylogeny of 33 isolates of various Boeremia exigua varieties, 17 isolates of other Boeremia species and 13 isolates of Boeremia lilacis, including 10 isolates used in this study (marked with asterisks). The tree was rooted to Phoma herbarum (strain: CBS 615.75). Bootstrap support values (1000 replicates) are indicated at the nodes. The scale bar represents 0.02 substitutions per site

g). Non-normal distribution of the lesion length on shoots was detected in the Shapiro-Wilk test $(\mathrm{W}=$ $0.930, p=0.002)$. Also no differences in lesion length on shoots caused by different strains proved to be statistically significant according to the multiple comparisons post hoc test following KruskalWallis analysis of ranks (Fig. 5a).

Mean length of lesions, 6 weeks post inoculation, reached from $15.50 \mathrm{~mm}$ (strain Js 6731) to $24.17 \mathrm{~mm}$ (Js 6915) (Table 2). Necrotic areas were always elongated with only slight variation is shape (Fig. 4a-g). For most shoots necrosis margin was regular (Fig. 4b-d), only occasionally irregular with wedge shaped indentations (Fig. 4a). Necrotic area for $21.7 \%$ of shoots was slightly depressed, while for $6.7 \%$ depression was distinct (Fig. 4d). The reminding strip of living bark opposite the inoculations sites measured 2-5 mm, except four shoots, on which necrosis girdled the entire circumference of the shoot. Only two of these four developed a noticeable narrowing of necrotic section (Fig. 4f). However, no dieback of the entire distal segments of the shoots was observed.

All necroses on shoots resulted in discoloration of the tissue (Fig. 4a-g), generally to uniformly brown (Fig. 4d), or light-brown in the middle and darkbrown closer to the edge (Fig. 4b). B. lilacis pycnidia developed on $15.0 \%$ of necroses.

\section{Inoculated petioles}

Boeremia lilacis caused extensive necrotic lesions on all inoculated $F$. excelsior leaf petioles (Table 2, Fig. $4 \mathrm{i}-\mathrm{o}$ ). The results of Shapiro-Wilk (W=0.966, $p=$ 0.098) test did not allow to reject the hypothesis of the normal distribution of lesion length on petioles. The lesion length on petioles was significantly higher than lesion length on shoots according to Mann-Whitney test $(\mathrm{U}=938.0000, p<0.05)$. The length of lesions caused on petioles proved to be significantly different among strains in the multiple comparisons post hoc test following Kruskal-Wallis analysis of ranks (Fig. 5b). Among the studied fungal isolates, strain Js 9032 produced notably longer lesions than strains Js 6731 and Js 6738 (Fig. 5b). Occasionally, the extension of the necrosis, ceased upon insertion of leaflet petiolules (Fig. 4i). The opposite side of inoculation site remained alive on most petioles with $1-3 \mathrm{~mm}$ of viable tissue. For $11.7 \%$ of petioles, however, the necrosis girdled their entire circumference (Fig. $4 \mathrm{k}-\mathrm{m}$ ) resulting in wilting of the distal parts (Fig. $4 \mathrm{~m}$ ). No dieback of 

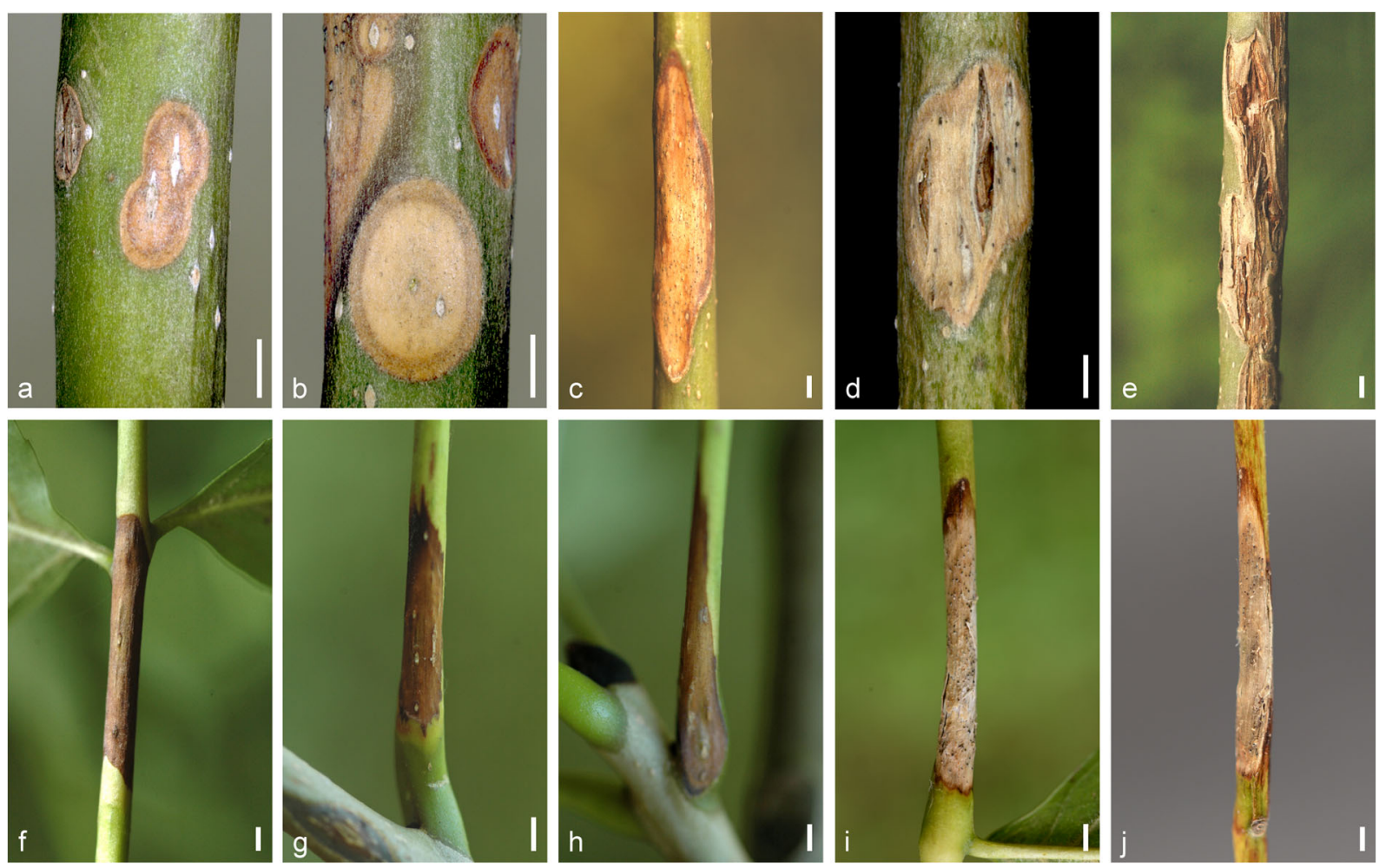

Fig. 3 Natural necrotic lesions on Fraxinus excelsior associated with Boeremia lilacis: a-e necrotic lesions on epicormic shoots, $\mathbf{f - j}$ necrotic lesions on leaf petioles / rachises without pycnidia (f-h) and with pycnidia (i-j), further details in the text, bar $=2 \mu \mathrm{m}$

the distal sections of the leaves was observed at the time of harvest.

Necrosis of petiole tissue resulted in uniformly brown discoloration (Fig. $4 \mathrm{j}, \mathrm{k}$ ), that could be accompanied by lighter areas (Fig. 41, o). B. lilacis pycnidia developed on $43.3 \%$ of petioles. They occupied just the central part (Fig. 4i, n), or most of necrotic area, approaching the living tissue (Fig. 4o).

\section{Reisolations and controls}

Boeremia lilacis was detected in all of inoculated shoots and petioles of $F$. excelsior. From 270 explants originating from shoots and 270 explants originating from petioles $88.1 \%$ and $80.7 \%$, respectively, yielded B. lilacis colonies. All the re-isolated colonies showed the same characteristics as observed previously for isolates used in inoculations. Except B. lilacis, species of genera: Alternaria, Cladosporium, Colletotrichum, Epicoccum, Fusarium, Lecytophora, and Phomopsis were isolated from necrotic areas.
None of control shoots and petioles developed necroses (Fig. 4h, p). Four control wounds on shoots and five control wounds on petioles healed completely at the time of evaluation, for the rest the healing was incomplete. None of the B. lilacis cultures were isolated from any of the mock inoculations, regardless of host organ.

Fig. 4 Appearance of the necrotic lesions on shoots (a-g) and leaf petioles (i-o) of Fraxinus excelsior six weeks after wound inoculation with Boeremia lilacis: a - necrotic lesion with the margin irregularly notched with wedge shaped indentations, b necrotic lesion, regular elliptical shape, $\mathbf{c}$ - necrotic lesion with depression, d - necrotic lesion with depression and girdling the shoot, e-f - shoot lacking a live strip of the bark opposite the inoculation wound, without distinct depression (e) and with distinct depression (f), $\mathbf{g}$ - ripe pycnidia of B. lilacis developed on the necrotic tissue, $\mathbf{h}$ - control shoot without necrotic lesion, $\mathbf{i}$ - the extension of the necrosis, ceased upon insertion of a leaflet petiolules, $\mathbf{j}-\mathbf{I}$ - necrotic lesion with dark brown (j-k) and light (I) discoloration of the tissue, $\mathbf{m}$ - wilting of the distal parts of the leaf, $\mathbf{n}$ - ripe pycnidia on necrotic tissue developed close to inoculations wound, $\mathbf{o}$ - ripe pycnidia on necrotic tissue approaching the live tissues, $\mathbf{p}$ - control petiole without necrotic lesion, bar $=5 \mu \mathrm{m}$ 

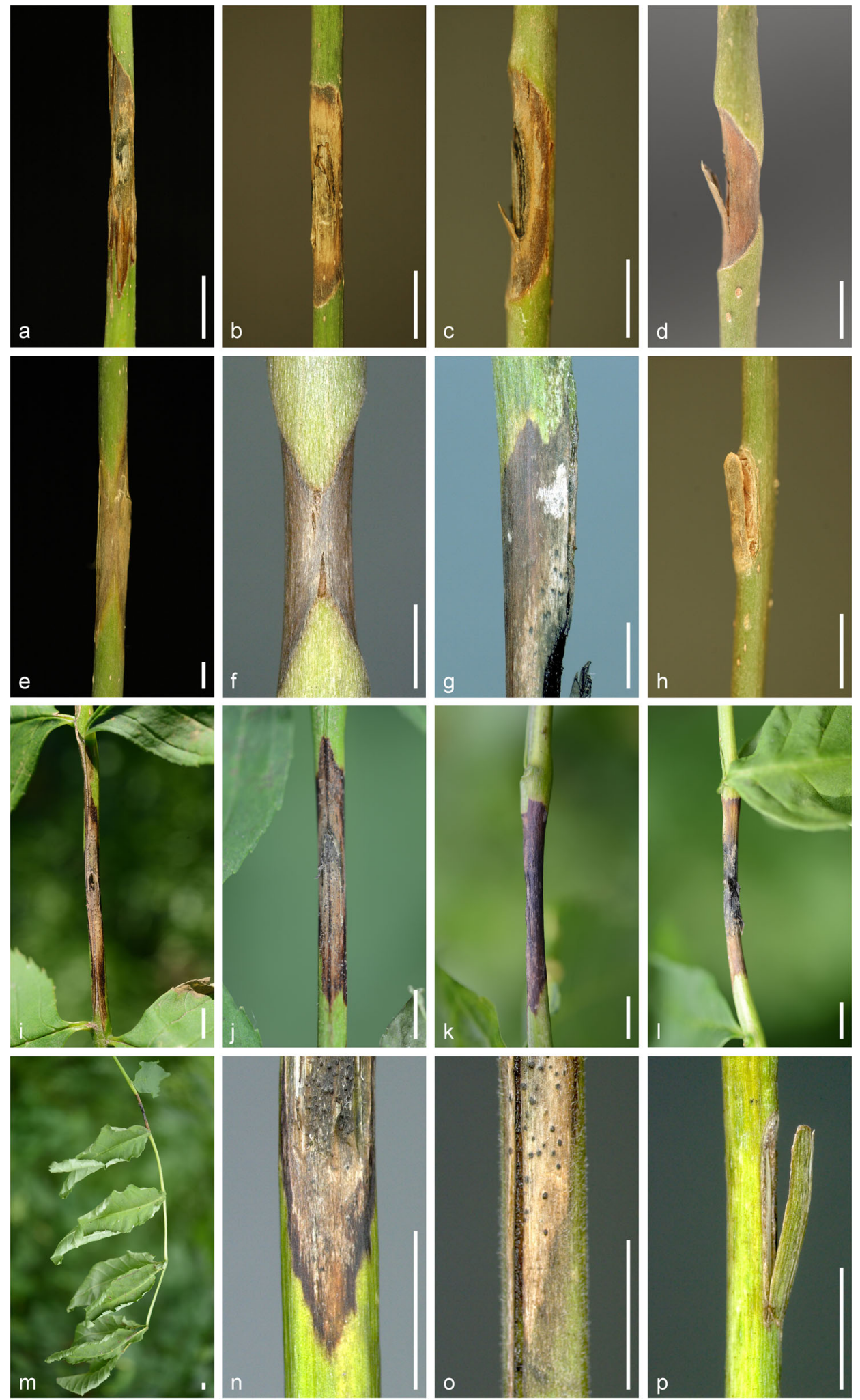

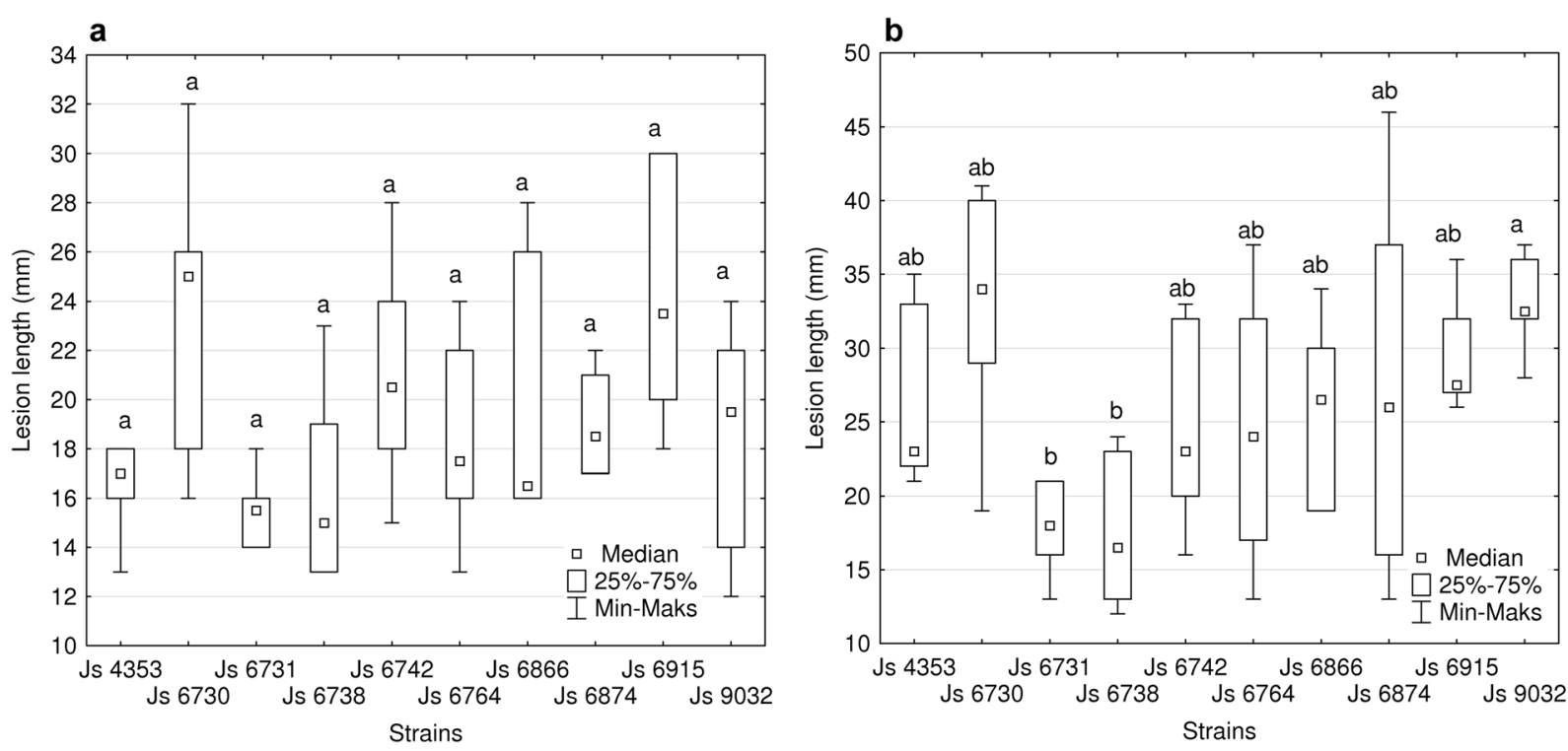

Fig. 5 Lesion development on shoots (a) and on petioles (b) of Fraxinus excelsior. Variables sharing the same letter were not significantly different at $p \leq 0.05$ according to the multiple comparisons post hoc test following the Kruskal-Wallis rank test

\section{Discussion}

Identification of Boeremia lilacis on Fraxinus excelsior

The initial assumption during the study on the aetiology of necrotic lesions observed since 2010 on F. excelsior in southern Poland was that this symptom is caused by Boeremia exigua. These was indicated by either the traits of fructification (pycnidia with conidia) on the natural necrotic lesions and the morphology of isolated cultures. This was not unexpected as the species was reported on $F$. excelsior previously from various regions (Schmitz et al. 2006; Kowalski et al. 2016; Bakys et al. 2009; Trapiello et al. 2017). B. exigua var. exigua as the cause of lesions was, however, ruled out in further studies and physiological tests. The $\mathrm{NaOH}$ reaction (application in a droplet on the colony margin) was negative indicating no antibiotic E production, a trait characteristic to var. exigua (Boerema et al. 2004). The combined phylogeny of ITS, ACT, TUB and EF1- $\alpha$ showed that our isolates belonged to Boeremia lilacis (Sacc.) Q. Chen \& L. Cai. Based on these data they are clearly distinct from $B$. exigua varieties and form a discrete clade in our cladogram. This conclusion was also confirmed by the pairwise distance analysis between Polish isolates and the rest of Boeremia isolates. Although the sequences obtained for Polish isolates are not fully identical to other isolates of $B$. lilacis, our cladogram still contains two big clades: one comprised of B. lilacis (including Polish isolates) and the second clade comprised of all other Boeremia species/varieties.

Boeremia lilacis was elevated to the species level based on the multi-gene phylogeny of the Boeremia exigua varieties (Berner et al. 2015; Chen et al. 2015). It was previously recognised either as Phoma exigua var. lilacis (Sacc.) Boerema or Boeremia exigua var. lilacis (Sacc.) Aveskamp et al. (Aa et al. 2000; Aveskamp et al. 2010). The species was known to date as a pathogen of lilac (Syringa vulgaris), causing damping-off of seedlings, leaf necroses and dieback of shoots. It has been also isolated occasionally from necrotic tissue of a Forsythia hybrids and once from Philadelphus sp. leaves (Boerema et al. 2004; Chen et al. 2015). The list of confirmed records on lilac include isolates originating from France, Germany, Italy, the Netherlands, USA and New Zealand (Aa et al. 2000). In the present work we demonstrate that the host range includes also $F$. excelsior. This may suggest that the $B$. lilacis host range is primarily restricted to a single family: Oleaceae. This kind of narrow host range is characteristic to most of $B$. exigua varieties, except var. exigua and var. gilvescens that both infect many plant species from various families (Aa et al. 2000; Boerema et al. 2004). 
Pathogenicity of Boeremia lilacis towards Fraxinus excelsior

All B. lilacis isolates used in pathogenicity test caused tissue necroses on all inoculated shoots and petioles. Among the fungi, whose pathogenicity toward F. excelsior was tested using similar methods, only two species proved to be as effective: Hymenoscyphus fraxineus and Cytospora pruinosa. Other tested species caused necroses only on $16.7 \%$ (Fusarium solani) to $73.3 \%$ (Diplodia mutila) of ash shoots (Kowalski et al. 2017). Thus, the results of our pathogenicity test proved $B$. lilacis to be a highly pathogenic species. An average length of necroses on shoots after six weeks ranged from 15.50 to $24.17 \mathrm{~mm}$. While an average lesion length on cuttings of Populus $\times$ euramericana 'Robusta' caused by Phoma exigua var. populi after 36 days under greenhouse condition ranged from 12.8 to $16.4 \mathrm{~mm}$ (De Gruyter and Scheer 1998). Thus, the necroses caused by these two fungi were rather similar in size.

Pycnidia were the only sporulation structures produced by $B$. lilacis in the studied stands, so natural infections were generally conidia-mediated. The host plant reacts to the natural infection by an activation of various resistance mechanisms, what leads to various forms of host-pathogen interactions (Gómez-Gómez 2004). Therefore, pathogenicity tests consisting of an artificial inoculation in wounds do not completely model natural processes, as could be the case with many other Boeremia spp., that are considered wound pathogens (Aa et al. 2000; Boerema et al. 2004). According to Aa et al. (2000), on lilac, B. lilacis may act as a secondary pathogen following bacterial blight caused by Pseudomonas syringae. This observation indicates that bark damage may favour the $B$. lilacis infection.

Hymenoscyphus fraxineus caused longer necroses on stems of $F$. excelsior than on leaf petioles in artificial inoculation test (Kowalski et al. 2015). For B. lilacis this pattern is reversed; the size of necroses on petioles of F. excelsior proved to be statistically significantly bigger than the size on shoots. Single necroses on epicormic shoots originating from natural infections of $B$. lilacis also tended to be small in most cases, extensive necrotic lesions were often the result of their merging (Fig. 3). The necrotic bark discoloration following artificial inoculations was generally identical to this after natural infections. Interesting in this context are extremely dark brown discolorations observed on some petioles following both, natural infection (Fig. 3) and artificial inoculation (Fig. 4). This feature may be dependent on the metabolites produced. The in vitro colonies of the tested isolates produced different amounts of the substance visible as white crystals, possibly a toxin affecting the host tissues. Phoma exigua varieties are known to produce phytotoxin and anthraquinone pigments as secondary metabolites (Boerema et al. 2004; Rai et al. 2009). The properties and role of the crystalline substance produced by $B$. lilacis require further study.

At the time of final evaluation of inoculated plants of F. excelsior no dieback of distal parts of shoots nor petioles were observed. Only occasionally leaves began to wilt after six weeks (Fig. 4). Expectedly, the shoots without a strip of living tissue left opposite the inoculation site (Fig. 4), would die above this point later on.

It took B. lilacis a few weeks to produce in necrotic areas pycnidia with mature conidia (Figs. 3 and 4), a ready source of the infectious material. It is probable that the infectious material produced in the analysed stands on epicormic shoots from 2010 was the source of infection causing the new type of $B$. lilacis associated necrosis occurring on ash leaf petioles since 2013 (Fig. 3).

The current observations concern the damage caused by $B$. lilacis to epicormic shoots. It cannot be ruled out, however, that also thin shoots in the crowns of older trees, seedlings in natural regeneration of ash and nurseries could be damaged. Boudier (1994) and Schmitz et al. (2006) reported the massive die-off of Fraxinus spp. seedlings in Belgium and France in the 90 s that was attributed to P. exigua. The inoculation test demonstrated the phytopathogenic character of $P$. exigua to one-year-old $F$. excelsior seedlings (Schmitz et al. 2006). P. exigua was also successfully reisolated from all lesions, thereby completing Koch's postulates (Schmitz et al. 2006).

Similar results were achieved in the current study, after 6 weeks B. lilacis was re-isolated from all shoots and all petioles. This result indicates that the B. lilacis mycelium adapts well in the ash tissues. For some ashinfecting fungi, e.g. Hymenoscyphus fraxineus, the likelihood of successful re-isolation from a necrotic lesion decrease with time (Kowalski and Holdenrieder 2009; Kowalski et al. 2017).

Boeremia lilacis vs. ash decline (H. fraxineus)

For B. lilacis the extension of necrotic lesions from their starting point, both on shoots and petioles, was 
limited compared to $H$. fraxineus caused necroses. Because of that B. lilacis only occasionally caused death of distal parts of leaves and petioles. Dead shoots were observed only where multiple small local necroses coalesced forming large affected areas (Fig. 3). Leaves and shoots often die as a result of $H$. fraxineus infection, as was shown in artificial inoculation experiments where $42 \%$ of shoots and $35.2 \%$ of distal parts of rachises were killed after eight weeks (Kowalski and Holdenrieder 2009; Kowalski et al. 2015). Lesions on shoots caused by B. lilacis were round, oval, or shortly elliptical, with fairly uniformly brown necrotic tissue in the central part of necrosis. Initially necroses were often formed around lenticels (Fig. 3). This observation suggests that lenticels could be one of the ways of natural infection. $H$. fraxineus necroses are elongated with necrotic tissue either uniformly light brown discolorated or with dark-brown zones. They are often located at the base of the lateral branch or just below the leaf petiole, as a result of the mycelium spreading from petiole into shoot (Gross et al. 2014; Cleary et al. 2013; McKinney et al. 2014). In addition, dark-brown discoloration of $B$. lilacis necrotic tissue observed on ash leaf petioles (Fig. 3), generally not recorded for $H$. fraxineus lesions (Kowalski and Holdenrieder 2009; Cleary et al. 2013; Kowalski et al. 2015; Drenkhan et al. 2017), was retained for long time. It was only late in the vegetation period when straw-coloured necrotic areas were sporadically observed (Fig. 3).

The difference between $B$. lilacis and $H$. fraxineus caused necroses pertains also to etiological sings developed. B. lilacis often produces conidia-filled pycnidia directly on the necrotic tissue (Fig. 3), while $H$. fraxineus usually does not develop any kind of sporulation within necrotic areas, Chalara type phialides on the black pseudosclerotium are produced only occasionally (Kowalski and Holdenrieder 2009).

From the viewpoint of the ash decline epidemiology, the abundant production of epicormic shoots on trunks is disadvantageous. This is because they are a suitable entry points for $H$. fraxineus infections making it easy to infect stems directly, what is dangerous for the life of the tree (Gross et al. 2014). The B. lilacis infection of epicormic shoots, although it involves tissue necrosis, may be a factor that would interrupt the transition of H. fraxineus from the distal part of the shoot to its base, and consequently to the trunk. The barrier in the form of dead tissue may be supported by a biochemical barrier, as many Boeremia spp. are known to produce secondary metabolites with antibiotic properties (Boerema et al. 2004; Schlegel et al. 2016; Kosawang et al. 2017).

Acknowledgements This work was supported by two projects concerning ash decline: project nos. 2011/03/B/NZ9/00078 and 2016/21/B/NZ9/01226, financed by the National Science Centre, Poland. The authors would like to thank Pawel Szczygiel, the Head of the Stary Sacz Forest District, for the permission to conduct the field experiments and his help during the research and two anonymous reviewers for their valuable comments and suggestions.

Open Access This article is distributed under the terms of the Creative Commons Attribution 4.0 International License (http:// creativecommons.org/licenses/by/4.0/), which permits unrestricted use, distribution, and reproduction in any medium, provided you give appropriate credit to the original author(s) and the source, provide a link to the Creative Commons license, and indicate if changes were made.

\section{References}

Aa, H. A., van der Boerema, G. H., \& de Gruyter, J. (2000). Contributions towards a monograph of Phoma (Coelomycetes) VI - 1. Section Phyllostictoides: Characteristics and nomenclature of its type species Phoma exigua. Persoonia, 17, 435-456.

Abeln, E. C. A., Stax, A. M., de Gruyter, J., \& van der Aa, H. A. (2002). Genetic differentiation of Phoma exigua varieties by means of AFLP fingerprints. Mycological Research, 106, 419-427.

Aveskamp, M. M., Woudenberg, J. H. C., de Gruyter, J., Turco, E., Groenewald, J. Z., \& Crous, P. W. (2009). Development of taxon-specific sequence characterized amplified region (SCAR) markers based on actin sequences and DNA amplification fingerprinting (DAF): A case study in the Phoma exigua species complex. Molecular Plant Pathology, 10, 403-414.

Aveskamp, M. M., de Gruyter, J., \& Woudenberg, J. H. C. (2010). Highlights of the Didymellaceae: A polyphasic approach to characterise Phoma and related pleosporalean genera. Studies in Mycology, 65, 1-60.

Bakys, R., Vasaitis, R., Barklund, P., Ihrmark, K., \& Stenlid, J. (2009). Investigations concerning the role of Chalara fraxinea in declining Fraxinus excelsior. Plant Pathology, 58, 284-292.

Baral, H.-O., \& Bemmann, M. (2014). Hymenoscyphus fraxineus vs. Hymenoscyphus albidus: A comparative light microscopic study on the causal agent of European ash dieback and related foliicolous, stroma-forming species. Mycology, 5, 228-290.

Baral, H.-O., Queloz, V., \& Hosoya, T. (2014). Hymenoscyphus fraxineus, the correct scientific name for the fungus causing ash dieback in Europe. IMA Fungus, 5, 79-80. 
Berner, D., Cavin, C., \& Woudenberg, J. H. C. (2015). Assessment of Boeremia exigua var. rhapontica, as a biological control agent of Russian knapweed (Rhaponticum repens). Biological Control, 81, 65-75.

Boerema, G. H., \& Höweler, L. H. (1967). Phoma exigua Desm. and its varieties. Persoonia, 5, 15-28.

Boerema, G. H., de Gruyter, J., Noordeloos, M. E. \& Hamers, M. E. C. (2004). Phoma Identification Manual. Differentiation of Specific and Infra-specific Taxa in Culture. (Wallingford, Oxfordshire, UK, CAB International: CABI Publishing).

Boudier, B. (1994). Le chancre des jeunes plants de frênes, une maladie grave certaines années mais des perspectives de lutte. Phytoma, 461, 35-36.

Brebaum, S. N., \& Boland, G. J. (1999). First report of Phoma herbarum and Phoma exigua as pathogens of dandelion in southern Ontario. Plant Disease, 83(2), 200.

Carbone, I., \& Kohn, L. M. (1999). A method for designing primer sets for speciation studies in filamentous ascomycetes. Mycologia, 91, 553-556.

Chen, J. (2012). Fungal community survey of Fraxinus excelsior in New Zealand. Dissertation, University of Agricultural Sciences, Uppsala, Swedish.

Chen, Q., Jiang, J. R., Zhang, G. Z., Cai, L., \& Crous, P. W. (2015). Resolving the Phoma enigma. Studies in Mycology, 82, 137-217.

Cleary, M. R., Daniel, G., \& Stenlid, J. (2013). Light and scanning electron microscopy studies of the early infection stages of Hymenoscyphus pseudoalbidus on Fraxinus excelsior. Plant Pathology, 62, 1294-1301.

De Gruyter, J., \& Scheer, P. (1998). Taxonomy and pathogenicity of Phoma exigua var. nov. populi causing necrotic bark lesions on poplars. Journal of Phytopathology, 146, 411-415.

Drenkhan, R., Solheim, H., Bogacheva, A., Riit, T., Adamson, K., Drenkhan, T., Maaten, T., \& Hietala, A. M. (2017). Hymenoscyphus fraxineus is a leaf pathogen of local Fraxinus species in the Russian Far East. Plant Pathology, 66, 490-500.

Farr, D. F., Bills, G. F., Chamuris, G. P., \& Rossman, A. Y. (1989). Fungi on plants and plant products in the United States. St Paul: APS Press.

Glass, N. L., \& Donaldson, G. C. (1995). Development of primer sets designed for use with the PCR to amplify conserved genes from filamentous ascomycetes. Applied and Environmental Microbiology, 61, 1323-1330.

Gómez-Gómez, L. (2004). Plant perception systems for pathogen recognition and defence. Molecular Immunology, 41, 1055-1062.

Gross, A., \& Han, J. G. (2015). Hymenoscyphus fraxineus and two new Hymenoscyphus species identified in Korea. Mycological Progress, 14, 1-13.

Gross, A., \& Sieber, T. (2016). Virulence of Hymenoscyphus albidus and native and introduced Hymenoscyphus fraxineus on Fraxinus excelsior and Fraxinus pennsylvanica. Plant Pathology, 65, 655-663.

Gross, A., Holdenrieder, O., Pautasso, M., Queloz, V., \& Sieber, T. N. (2014). Hymenoscyphus pseudoalbidus, the causal agent of European ash dieback. Molecular Plant Pathology, 15, 5-21.
Hasegawa, M., Kishino, H., \& Yano, T. (1985). Dating the humanape splitting by a molecular clock of mitochondrial DNA. Journal of Molecular Evolution, 22, 160-174.

Husson, C., Caël, O., Grandjean, J. P., Nageleisen, L. M., \& Marçais, B. (2012). Occurrence of Hymenoscyphus pseudoalbidus on infected ash logs. Plant Pathology, 61, 889-895.

Ibrahim, M., Sieber, T. N., \& Schlegel, M. (2017). Communities of fungal endophytes in leaves of Fraxinus ornus are highly diverse. Fungal Ecology, 29, 10-19.

Katoh, K., \& Standley, D. M. (2013). MAFFT multiple sequence alignment software version 7: Improvements in performance and usability. Molecular Biology and Evolution, 30, 772-780.

Kearse, M., Moir, R., Wilson, A., Stones-Havas, S., Cheung, M., Sturrock, S., Buxton, S., Cooper, A., Markowitz, S., Duran, C., Thierer, T., Ashton, B., Mentjies, P., \& Drummond, A. (2012). Geneious basic: An integrated and extendable desktop software platform for the organization and analysis of sequence data. Bioinformatics, 28, 1647-1649.

Khanuja, S. P. S., Shasany, A. K., Darokar, M. P., \& Kumar, S. (1999). Rapid isolation of DNA from dry and fresh samples of plants producing large amounts of secondary metabolites and essential oils. Plant Molecular Biology Reporter, 17, 1-7.

Kosawang, C., Amby, D. B., Bussaban, B., McKinney, L. V., Xu, J., Kjær, E. D., Collinge, D. B., \& Nielsen, L. R. (2017). Fungal communities associated with species of Fraxinus tolerant to ash dieback, and their potential for biological control. Fungal Biology, 122, 110-120. https://doi. org/10.1016/j.funbio.2017.11.002.

Kowalski, T. (2006). Chalara fraxinea sp. nov. associated with dieback of ash (Fraxinus excelsior) in Poland. Forest Pathology, 36, 264-270.

Kowalski, T., \& Holdenrieder, O. (2009). Pathogenicity of Chalara fraxinea. Forest Pathology, 39, 1-7.

Kowalski, T., \& Kehr, R. (2016). Stand des Eschentriebsterbens und zunehmende Schäden an Buche und Berg-Ahorn. In D. Dujesiefken (Ed.), Jahrbuch der Baumpflege (pp. 63-83). Braunschweig: Haymarket Media.

Kowalski, T., Bilański, P., \& Holdenrieder, O. (2015). Virulence of Hymenoscyphus albidus and $H$. fraxineus on Fraxinus excelsior and F. pennsylvanica. PLoS One, 10(10), e 0141592. https://doi.org/10.1371/journal.pone.0141592.

Kowalski, T., Kraj, W., \& Bednarz, B. (2016). Fungi on stems and twigs in initial and advanced stages of dieback of European ash (Fraxinus excelsior) in Poland. European Journal of Forest Research, 135, 565-579.

Kowalski, T., Bilański, P., \& Kraj, W. (2017). Pathogenicity of fungi associated with ash dieback towards Fraxinus excelsior. Plant Pathology, 66, 1228-1238.

Kumar, S., Stecher, G., \& Tamura, K. (2016). MEGA7: Molecular evolutionary genetics analysis version 7.0 for bigger datasets. Molecular Biology and Evolution, 33, 1870-1874.

McKinney, L. V., Nielsen, L. R., Collinge, D. B., Thomsen, I. M., Hansen, J. K., \& Kjaer, E. D. (2014). The ash dieback crisis: Genetic variation in resistance can prove a long-term solution. Plant Pathology, 63, 485-499.

Power, M. W. P., Hopkins, A. J. M., Chen, J., Bengtsson, S. B. K., Vasaitis, R., \& Cleary, M. R. (2017). European Fraxinus species introduced into New Zealand retain many of their native endophytic fungi. Baltic Forestry, 23, 74-81. 
Queloz, V., Grünig, C. R., Berndt, R., Kowalski, T., Sieber, T. N., \& Holdenrieder, O. (2011). Cryptic speciation in Hymenoscyphus albidus. Forest Pathology, 41, 133-142.

Rai, M., Deshmukh, P., Gade, A., Ingle, A., Kövics, G. J., \& Irinyi, L. (2009). Phoma Saccardo: Distribution, secondary metabolite production and biotechnological applications. Critical Reviews in Microbiology, 35, 182-196.

Rozas, J., Ferrer-Mata, A., Sánchez-DelBarrio, J. C., Guirao-Rico, S., Librado, P., Ramos-Onsins, S. E., \& Sánchez-Gracia, A. (2017). DnaSP 6: DNA sequence polymorphism analysis of large data sets. Molecular Biology and Evolution, 34, 3299-3302.

Schlegel, M., Dubach, V., von Buol, L., \& Sieber, T. N. (2016). Effects of endophytic fungi on the ash dieback pathogen. FEMS Microbiology Ecology, 92. https://doi.org/10.1093 /femsec/fiw142.

Schmitz, S., Zini, J., Etienne, M., Moreau, J.-M., Chandelier, A., \& Cavelier, M. (2006). Effectiveness of thiophanatemethyl, trifloxystrobin and vinclozolin on canker caused by Phoma exigua Desm. On ash tree seedlings. Biotechnologie Agronomie Societe et Environement, 10, 25-31.
Skovsgaard, J. P., Thomsen, I. M., Skovgaard, I. M., \& Martinussen, T. (2010). Associations among symptoms of dieback in even-aged stands of ash (Fraxinus excelsior L.). Forest Pathology, 40, 7-18.

Tamura, K., Nei, M., \& Kumar, S. (2004). Prospects for inferring very large phylogenies by using the neighbor-joining method. Proceedings of the National Academy of Sciences (USA), 101, 11030-11035.

Timmermann, V., Børja, I., Hietala, A. M., Kirisits, T., \& Solheim, H. (2011). Ash dieback: Pathogen spread and diurnal patterns of ascospore dispersal, with special emphasis on Norway. EPPO Bulletin, 41, 14-20.

Trapiello, E., Schoebel, C. N., \& Rigling, D. (2017). Fungal community in symptomatic ash leaves in Spain. Baltic Forestry, 23, 68-73.

White, T. J., Bruns, T. D., Lee, S., \& Taylor, J. (1990). Amplification and direct sequencing of fungal ribosomal RNA genes for phylogenetics. In M. A. Innis, D. H. Gelfand, J. J. Sninsky, \& T. J. White (Eds.), PCR Protocols: A Guide to Methods and Applications (pp. 315322). New York: Academic Press. 